\title{
Leaf Spring Damages Analysis on Four Wheel Vehicle
}

\author{
Media Nofri \\ Program Studi Teknik Mesin (S-1) Fakutas Teknik \\ Universitas Tama Jagakarsa, Jakarta
}

\begin{abstract}
Leaf spring is a component that accept dynamic loads and provide driving comfort. Leaf springs that have been used for a long time will experience a decrease in the quality that causes fracture. The test of leaf spring includes chemical composition, hardness, fractography and metallography. The results show leaf spring is medium carbon steel of $0.47 \% \mathrm{C}$, the average hardness value of broken leaf springs is 419.7 means does not experience significant changes, the microstructure of broken leaf springs was tempered martensitic, has corrosion attack, trans granular cracking, secondary crack and crevice corrosion, and the fracture first occurred in the upper position of the middle leaf springs, while the remaining fractures were at the edges, there was also a corrosion attack on the bottom of the leaf springs, forming rough holes. The initial fracture is marked by the presence of a beach mark. This shape is a characteristic of fatigue fracture.
\end{abstract}

Keywords: chemical composition, hardness, metallography, fractography

DOI: $10.7176 / \mathrm{CPER} / 63-04$

Publication date:October $31^{\text {st }} 2020$

\section{Introduction}

Today's technology development is very fast, one of which is in the automotive sector. The comfort and safety of the driver and passengers are the main factors besides the reliability of the car engine itself. This encourages the automotive industries to compete in producing a good quality automotive product. The comfort and safety of motorized-vehicle riders, especially four-wheeled vehicles, must be guaranteed either directly or indirectly, especially since this vehicle is used as public transportation. This is intended so that drivers and passengers do not experience disturbance which may result in injury or pain while driving the vehicle.

One of the components that plays an important role in providing comfort to four-wheeled motorists is leaf spring. Leaf spring is a component that functions to accept dynamic loads and provide driving comfort. Leaf springs that have been used for a long time will experience a decrease in mechanical properties due to the dynamic load they receive. From some case studies, the occurrence of leaf spring breakage in its layer 1 of 5 leaf spring blades frequently happens to the spring that has been used for 11 years. This can be due to the use of leaf springs that have exceeded their service life, extreme road conditions, corrosion, it can also be due to excessive loading. For this reason, chemical composition tests, hardness tests, metallographic tests at two fault locations and fractography tests need to be carried out to determine and conclude the type of the fracture and its causes.

\section{Literature Review}

\subsection{Leaf Spring}

Leaf spring (fig. 1) serves to dampen the shock generated from the road surface. This type of spring able to receive a greater load when compared to other springs such as coil springs and torsion springs. Therefore, leaf springs are widely used in rear suspension systems in vehicles.

Leaf springs works when the rear wheels receive a shock from the road surface. It forwards the shock to the rear axle housing which results in an elongation of the leaf springs or the springs changes shape from an ellipse to a straight line which constructed with spring swing. To smoothen the excessive leaf spring squeezing process, this suspension is equipped with a vibration damper that is attached between the spring supports.

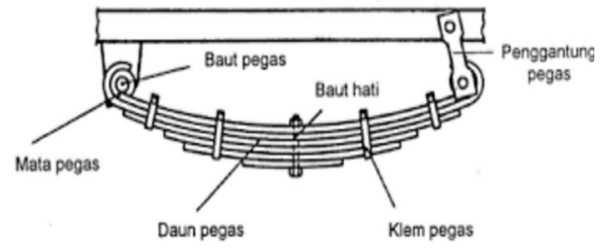

Figure 1. Leaf spring

The leaf spring suspension system (fig. 2) is a mechanism that is installed between the frame (body) and wheels that functions to withstand and dampen shocks. Besides being beneficial for the age of the vehicle, the suspension is also very useful for drivers and passengers so that they are more comfortable driving the vehicle. Wheel vibration on a vehicle, or in car is generally, defined as a movement that occurs in the spring weight. Spring weight is the weight of the car with the suspension system carrying. The motion that causes the front and rear ends of the car to move around the center of gravity of the vehicle is called pitching, the motion of the vehicle swinging 
from right to left is called rolling, while the movement of the car up and down is called bouncing.

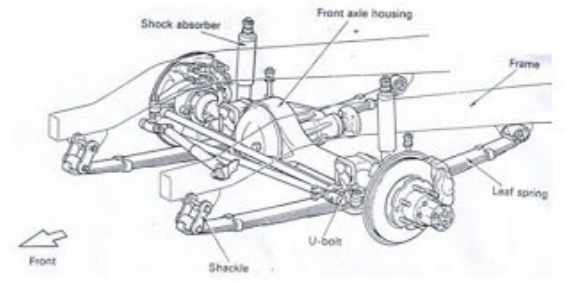

Figure 2. Leaf spring suspension on four-wheeled vehicle

The basis theory of leaf springs is a spring that focuses on strength so that it can receive large loads. The springs used are semi-epticical springs, with 5 spring blades on each wheel. The thickness of each spring sheet is approximately $28 \mathrm{~mm}$ with different lengths. The spring sheets are held together using fastening bolts at the center of the spring and the clamp. At both ends of spring number 1 (the longest spring), a hole is made as a place to tie the leaf spring to the vehicle frame.

The load received by the leaf spring is a dynamic load. It is a load that varies according to time, while static load is a fixed load in its size, working point and working line direction. The leaf spring suspension components are shock absorbers, U bolt, inner clip, U bolt plate, stand unit, rubber coating, core bolt, and lower and upper arm. Load on leaf springs is counted by the empty vehicle weight equals to $880 \mathrm{~kg}$ with leaf springs consist of 2 sets between left and right, each set totaling 5 spring steel blades, so that the value of each set of leaf springs is, $880 \mathrm{~kg}$ $/ 2=440 \mathrm{~kg}$. Each leaf blade receives a load of $(440 \mathrm{~kg}) / 5=88 \mathrm{~kg}$.

\subsection{Steel}

Steel is used in modern equipment that requires materials with high impact strength and wear resistance, due to the increased rotational speed and linear movement as well as the increased frequency of loading on components that are applied to modern machines today. Steel contains the same main elements as iron, namely Fe, with only the carbon content alone distinguishes them. The use of iron and steel today is very wide ranging from simple tools such as spoons and forks, to modern tools and machines such as gears and excavators.

Iron and steel are metals that are widely used in the integration of the iron (Fe) element with other elements that are always there such as; Carbon, Manganese, Silicon, Phospor, Sulfur and others. Iron and steel can be distinguished according to their carbon content. Steel has a carbon content less than $1.7 \%$, while iron has a carbon content greater than $1.7 \%$. Steel has other elements that can affect its the properties.

The addition of elements in carbon steel with one or more elements, depending on the characteristics of the carbon steel to be made. Medium carbon steel contains carbon elements between $0.35 \%-0.50 \%$. Carbon steel is being widely used for tool tools and machine parts. Based on the percentage of carbon contained in this steel, medium carbon steel can be used for the following a) Medium carbon steel containing $0.40 \% \mathrm{C}$ is used for industrial purposes, for example to make crankshafts, piston rods and so on; b) Medium carbon steel containing $0.50 \% \mathrm{C}$ is used to make gears, hammerheads and clams; and c) Medium carbon steel containing $0.55-0.60 \% \mathrm{C}$ is used to make springs

The equilibrium diagram or phase diagram (fig. 3) is a diagram for heat treatment of metals, and the ironcarbon phase diagram is applied to steel. The phase diagram shows the relationship of the microstructure to the mechanical properties of a material, all of which are related to the characteristics of the phase diagram.

From the phase diagram, it can be seen that the temperature around $723{ }^{\circ} \mathrm{C}$ is the temperature for the transformation of the austenite turns into the pearlite phase (which is a combination of the ferrite and cementite phases). This phase transformation is known as the eutectoid reaction and is the basis of the heat treatment process of steel. Meanwhile, the phase area where the percentage of carbon solution is up to $2 \%$ that occurs at a temperature of $1,147^{\circ} \mathrm{C}$ is the gamma iron region $(\gamma)$ or called as austenite which is stable, soft, ductile, easy to form and has a Face Centered Cubic (FCC) crystal structure.

Pure iron at temperatures below $910{ }^{\circ} \mathrm{C}$ has a Body Centered Cubic (BCC) crystal structure. BCC iron can dissolve carbon in very low amounts, which is about $0.02 \%$ maximum at $723{ }^{\circ} \mathrm{C}$. The solution at this intensity of the carbon in iron is also called alpha iron $(\alpha)$ or the ferrite phase. At temperatures between $910{ }^{\circ} \mathrm{C}$ to $1,390{ }^{\circ} \mathrm{C}$, the iron atoms arrange themselves into an FCC crystal form which is also called gamma iron $(\gamma)$ or the austenite phase. This gamma iron can dissolve large amounts of carbon, which is about $2.06 \%$ maximum at a temperature of around $1,147^{\circ} \mathrm{C}$. The addition of carbon to $\mathrm{FCC}$ iron was transformed into the $\mathrm{BCC}$ structure from $910^{\circ} \mathrm{C}$ to $723{ }^{\circ} \mathrm{C}$ at a carbon content of about $0.8 \%$. Between the temperature of $1,390{ }^{\circ} \mathrm{C}$ and the temperature of the liquid $1,534{ }^{\circ} \mathrm{C}$, gamma iron changes to a $\mathrm{BCC}$ structure called delta iron $(\delta)$. 


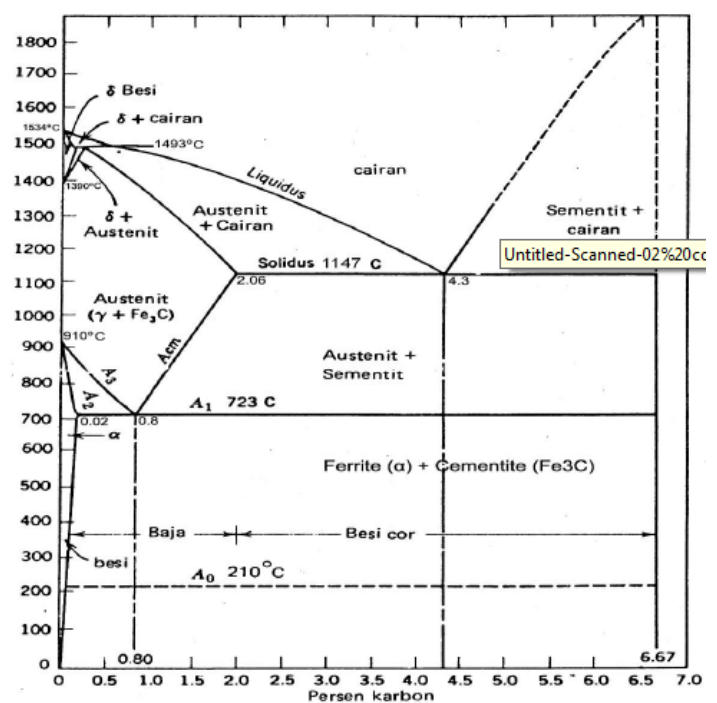

Figure 3. Iron - Carbon Phase Equilibrium Diagram

There are several things that need to be considered in the Fe-Fe3C diagram, namely, the change in the phase of ferrite or alpha iron $(\alpha)$, austenite or gamma iron $(\gamma)$, cementite or iron carbide, pearlite and cementite will be described below:

1. Ferrite or alpha $(\alpha)$ iron is a modification of the structure of pure iron at room temperature, where ferrite becomes soft and ductile because it has a BCC structure, then the space between the atoms is small and dense so that only a few carbon atoms can be accommodated.

2. Austenite or gamma iron $(\gamma)$ is a modification of pure iron with the FCC structure which has a greater atomic spacing than ferrite. However, the cavities in the FCC structure can barely accommodate carbon atoms. The insertion of carbon atoms will result in stress in the structure so that not all cavities can be filled, in other words, the solubility will be limited. Generally, the austenite phase is stable, ductile, malleable, non-ferromagnetic and has an FCC crystal structure.

3. Iron Carbide or Cementite is an iron-carbon alloy, where in this condition the carbon exceeds the solution limit so that it forms a second phase or iron carbide which has the $\mathrm{Fe} 3 \mathrm{C}$ composition. This is meaningless if the iron carbide forms $\mathrm{Fe} 3 \mathrm{C}$ molecules, but the crystal lattice that forms iron and carbon atoms has a ratio of 3: 1 . The carbide in ferrite will increase the hardness of the steel. The basic property of cementite is very hard.

4. Perlit is a special mixture that occurs in two phases which form austenization with an eutectoid composition transforming into ferrite and carbide. This is because ferrite and carbide are formed together and they come out mixed with each other. If the cooling rate is carried out slowly, the carbon atoms can diffuse longer and can travel further distances, so that the form of large pearlite is obtained. And if the cooling rate is accelerated even more, diffusion will be limited to a short distance so that it produces more thin layers.

5. Martensite is a phase that occurs due to very fast cooling, and occurs at temperatures below the eutectoid but still above room temperature. Because the structure of the FCC austenite is unstable, it will change to the BCT structure simultaneously. In this reaction there is no diffusion but there is a hardening (dislocation). all the atoms move simultaneously and this change is immediately very fast where all the remaining atoms remain in the solid solution because they are trapped in the lattice so that it is difficult to slip, so martensite will become strong and hard but brittle properties become high. Martensite can occur when the austenite is rapidly cooled (dipped) to a temperature below the formation of bainite.

\section{Methodology}

The test conducted in this study is using 2 samples, the fractured leaf spring sample (A) and the new leaf spring sample (B). Both samples are tested using the same methods following the steps:

1. Preparation of test objects

The test object used for this test is leaf spring number 1 of 5 leaf spring blades, made of medium carbon steel with a thickness of $6 \mathrm{~mm}$ and a length of $4 \mathrm{~cm}$

2. Chemical composition test

The chemical composition test is carried out to determine the elemental content chemical alloys in leaf springs. Tests were carried out using an Optical Emission Spectrometer machine. In the implementation of the test, radioactive rays and argon gas were fired against the specimens, then the results of the shooting 
were obtained which were read on a computer screen. The data generated in the chemical composition test shows the presence of several chemical elements.

3. Hardness test

Hardness is the resistance that is carried out by the material against the inward pressure caused by a pressing device with a certain shape under a certain influence, a small (or not deep) force indicates a large amount of hardness.

Hardness testing is conducted to determine the hardness of a material and it can also determine some other mechanical properties, such as strength. In hardness testing with the pressing method, a small pressure (identor) is pressed on the surface of the material to be tested with a certain pressure. The depth or result of pressing is a function of the hardness value. The softer a material is, the broader and deeper it is due to the great pressure, resulting in a small hardness value. There are several systems for testing material hardness, including Rockwell, Brinell and Vickers.

4. Metallography test

Metallographic test is a metal observation by observing the micro structure using a microscope. The microscope used is an optical microscope. From metallographic observations, the physical condition of the metal can be studied. Internal stresses in metals can be detected by observing the arrangement of the grains in which case the stress can be detected by the ratio of length increments. By studying and knowing the microstructure of a metal, the percentage of carbon contained and the maximum tensile stress can be determined. Metallographic analysis requires an representative metal sample that has undergone preparation which carried out in the order of selecting samples, mechanical cutting, shaping, marking, grinding, washing, polishing, etching, and then analyzed.

5. Fractography test

Fractographic test is used to determine the presence of material defects such as porosity, impurities, corrosion, and the rate of crack growth. Fractographic test also aims to determine the starting location of the initial damage or cracks. This test also to find out the type of damage, whether due to tensile, compressive, shear stresses, or others. Fractography testing is carried out using a stereo microscope which is useful for knowing the characteristics of the surface fracture on the broken leaf spring.

6. Data anysis

The results obtained from each test are then studied and the test results are compared between the fractured leaf spring sample (A) and the new leaf spring sample (B)

\section{Discussion and conclusion}

\section{DATA RESULT ANALYSIS AND DISCUSSION}

\section{Chemical Composition Test}

This test aims to determine the elements or alloy content contained in the material. Before the chemical composition testing process is carried out, the test sample is sanded and polished first until the surface is flat so that the process for the testing process can run well. The chemical composition testing process is carried out using a spectrometer.

Table 1. Result of chemical composition test on leaf spring
\begin{tabular}{|c|c|c|}
\hline \multirow{2}{*}{ No. } & \multirow{2}{*}{ Element } & Elemental content (\% weight) \\
\cline { 3 - 3 } & & Leaf Spring \\
\hline 1 & $\mathrm{Fe}$ & 97.52 \\
\hline 2 & $\mathrm{C}$ & 0.470 \\
\hline 3 & $\mathrm{Si}$ & 0.297 \\
\hline 4 & $\mathrm{M} \mathrm{N}$ & 0.677 \\
\hline 5 & $\mathrm{Cr}$ & 0.714 \\
\hline 6 & $\mathrm{Ni}$ & 0.105 \\
\hline 7 & $\mathrm{Mo}$ & 0.030 \\
\hline 8 & $\mathrm{Cu}$ & 0.121 \\
\hline 9 & $\mathrm{Al}$ & 0.027 \\
\hline 10 & $\mathrm{~V}$ & 0.007 \\
\hline 11 & $\mathrm{Ti}$ & 0.003 \\
\hline 12 & $\mathrm{Nb}$ & $<0.002$ \\
\hline 13 & $\mathrm{~S}$ & 0.007 \\
\hline 14 & $\mathrm{P}$ & 0.013 \\
\hline
\end{tabular}

Hardness Test

The Vickers method was chosen because it can measure macro hardness in which the hardness of the crystal can be determined, thus the Vickers test can get macro and micro hardness. To get results from Brinell or Rockwell, it 
can be converted.

The Vickers hardness test uses a diamond pyramid indenter which is essentially a square (fig. 4). The angle between the facing faces of the pyramid is $136^{\circ}$. The Vickers hardness figure is defined as the load divided by the surface area of the indentation. Practically, this area is calculated from microscopic measurements of the diagonal length of the trace. VHN can be determined from the following equation:

$$
\mathrm{VHN}=\frac{2 P \sin \left(\frac{\theta}{2}\right)}{d^{2}}=\frac{(1,854) P}{d^{2}}
$$

$\mathrm{P}=$ load used $(\mathrm{kg})$

$\mathrm{d}=$ average diagonal length $(\mathrm{mm})$

$\Theta=$ angle between the diamond faces that are face to face $=136^{\circ}$

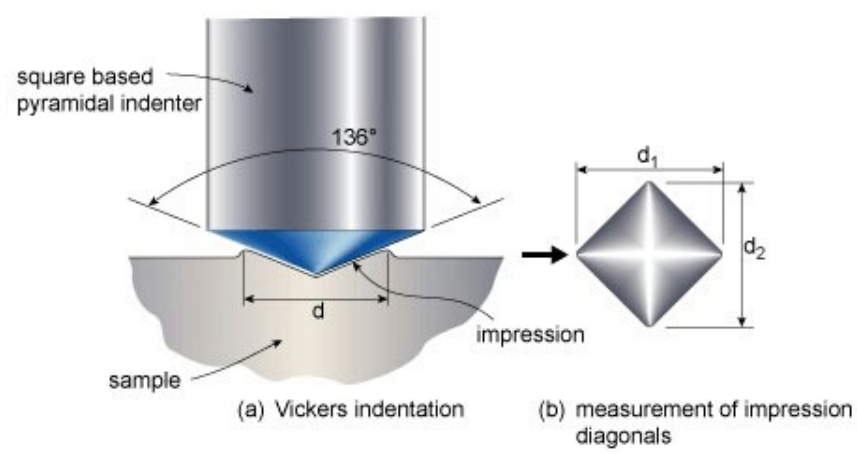

Figure 4. The Vickers Test Indenter

In the hardness test, there are 6 test points on the leaf spring sample (fig 5). From the results of hardness testing at 6 points of fractured leaf spring samples (A) and New Samples (B), there was no significant difference in the value of hardness as seen in Table 2.

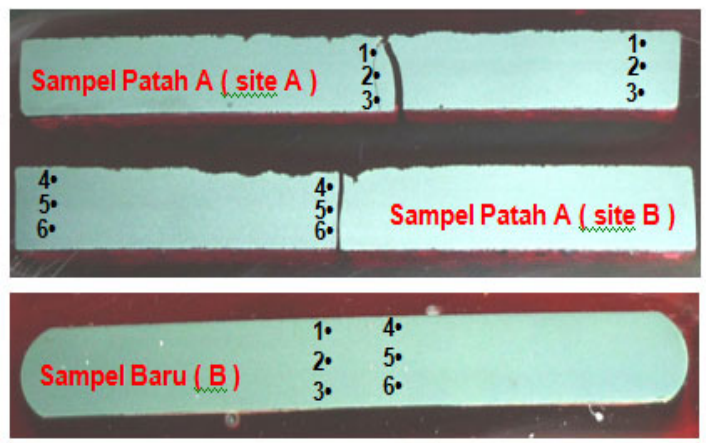

Figure 5. Hardness test point (fractured leaf spring sample - site A, fractured leaf spring sample - site B and new samples)

Table 2. Result of hardness test on leaf spring

\begin{tabular}{|c|c|c|c|}
\hline \multirow{3}{*}{ No } & \multicolumn{3}{|c|}{ Hardness value } \\
\hline & \multicolumn{2}{|c|}{ Fractured sample (A) } & \multirow{2}{*}{$\begin{array}{c}\text { New sample } \\
\text { (B) }\end{array}$} \\
\hline & Site A & Site B & \\
\hline 1 & 429 & 423 & 429 \\
\hline 2 & 412 & 423 & 423 \\
\hline 3 & 418 & 412 & 426 \\
\hline 4 & 423 & 415 & 428 \\
\hline 5 & 429 & 412 & 429 \\
\hline \multirow[t]{2}{*}{6} & 429 & 412 & 429 \\
\hline & 423.4 & 416.1 & \\
\hline Average & & & 427.3 \\
\hline
\end{tabular}

\section{Fractography Test}

The initial test carried out by conducting visual inspection / observation. This test is conducted to determine the shape of the fracture surface area and the type of fracture surface. Things that must be considered in this 
fractographic test is that the samples taken do not need to go through a preparation process such as sanding, polishing and so on, but only part of the sample is taken on the fractured surface and directly observed using a stereo microscope equipped with a digital camera. If it goes through the sample preparation process the fracture shape will be gone / changed. Result of Fractography test can be observed in figure 6 .

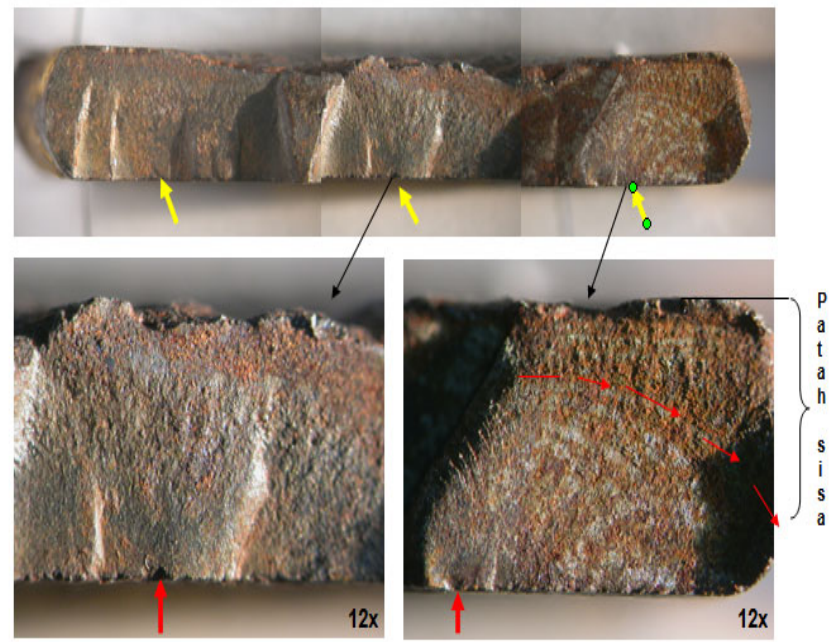

Figure 6. Result of fractography test on fractured leaf spring

\section{Metallographic Test}

Metallography is a technique or method of material preparation to measure, both quantitatively and qualitatively, the information contained in observable materials, such as phase, grain, chemical composition, grain orientation, atomic distance, dislocation, topography and so on.

In metallography, in general, two things will be observed, namely the macrostructure and the microstructure. Macrostructure is the structure of the metal that is visible macro on the etched surface of the polished specimen. Meanwhile, the microstructure is the structure of a specially prepared metal surface which is visible using a minimum magnification of $25 \mathrm{x}$.

Metallographic test equipment consists of several types of tools including grinding machine, polishing machine, and optical microscope. This metallographic testing method requires a fairly thorough and careful preparation, in order to obtain good test results. Therefore, several stages are needed in preparation, namely:

1. Cutting of Test Objects (Sample)

2. Mounting

3. Sanding (Grinding)

4. Polishing

5. Etching

6. Washing Process

7. Observation and Shooting

Metallographic test results are displayed in the form of metallographic photographs. The material (sample) tested was the fractured leaf spring (A) and the new leaf spring (B). Figures 7 to 9 are the results of microstructure testing in the form of metallographic photographs with magnifications of 50x, 100x, 200x and 500x using 2\% nital etching. In figure 7, is the microstructure of a broken sample leaf spring A (Edge site) with magnification of 50x, 200x and 500x. The following microstructure is a chronology of the break in leaf springs. 

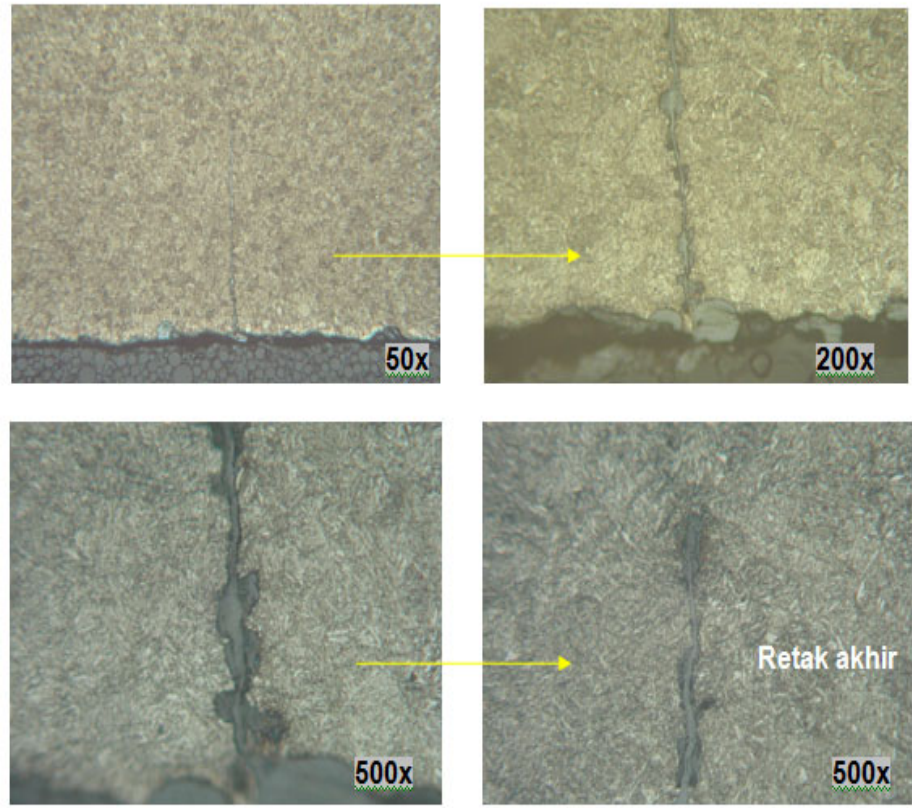

Figure 7. Micro structure of fractured leaf spring (edge site)
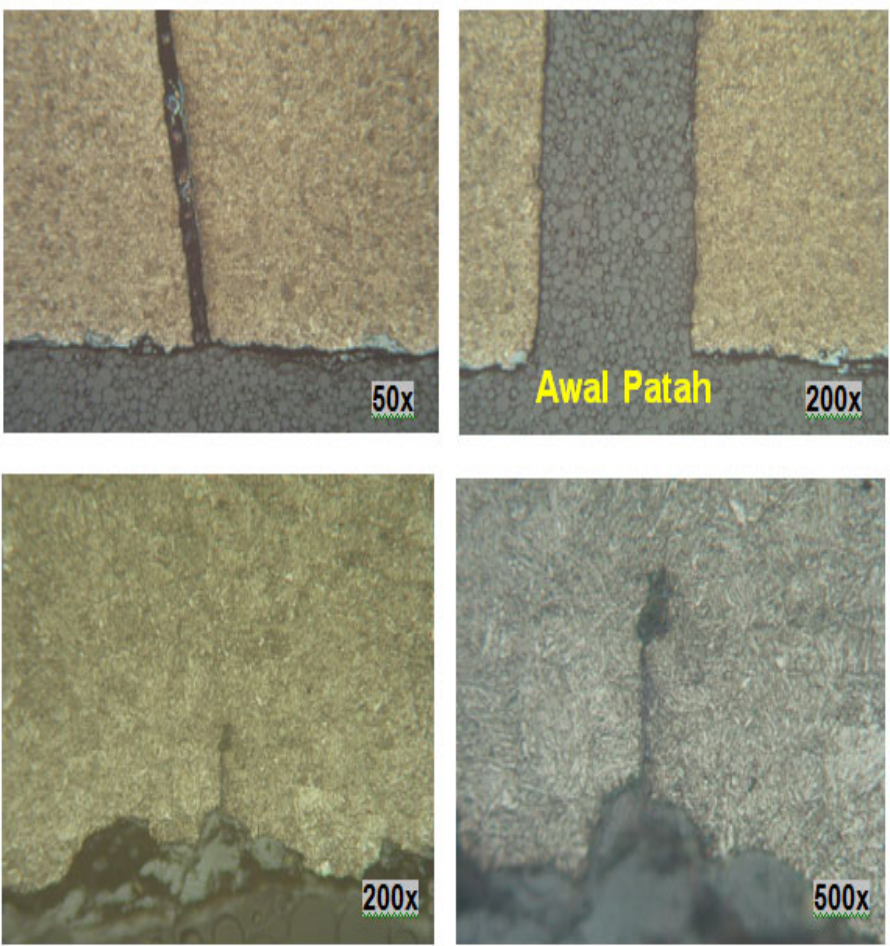

Figure 8. Micro structure of fractured leaf spring (middle site) 

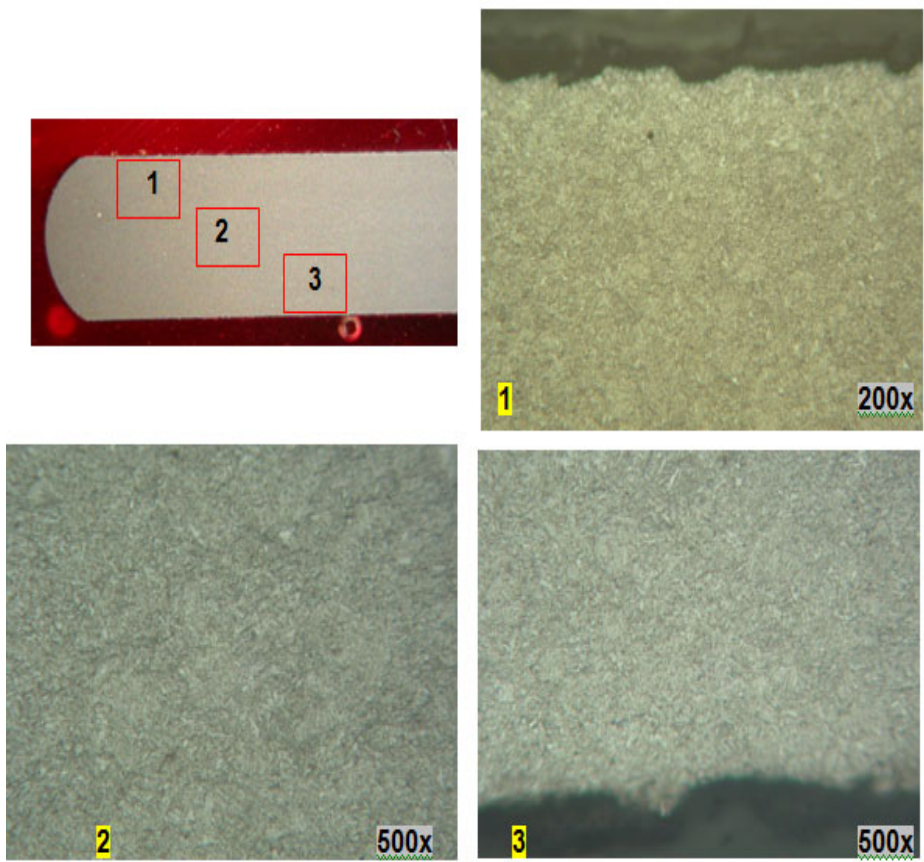

Figure 9. Micro structure of new leaf spring

\section{DATA ANALYSIS AND DISCUSSION}

\section{Basic Material of the Chemical Composition}

From the results of chemical composition testing on medium carbon steel leaf springs, there are types of alloys contained such as Iron $(\mathrm{Fe})$ alloy $97.52 \%$, chromium $(\mathrm{Cr})$ alloy $0.714 \%$, Manganese $(\mathrm{Mn})$ alloy $0.677 \%$, silicon (Si) alloy $0.297 \%$, Copper $(\mathrm{Cu})$ alloy $0.121 \%$ and Carbon (C) $0.470 \%$.

\section{Hardness Test}

From the results of the leaf spring hardness test, a graph can be made as shown in Figure 10. It shows the value of hardness, both in the fractured leaf spring material (Sample A) with an average of 419.7 and with new leaf springs (Sample B) with an average of 427.3. Meaning, it does not experience a significant change, the ratio value of leaf springs has no effect on hardness.

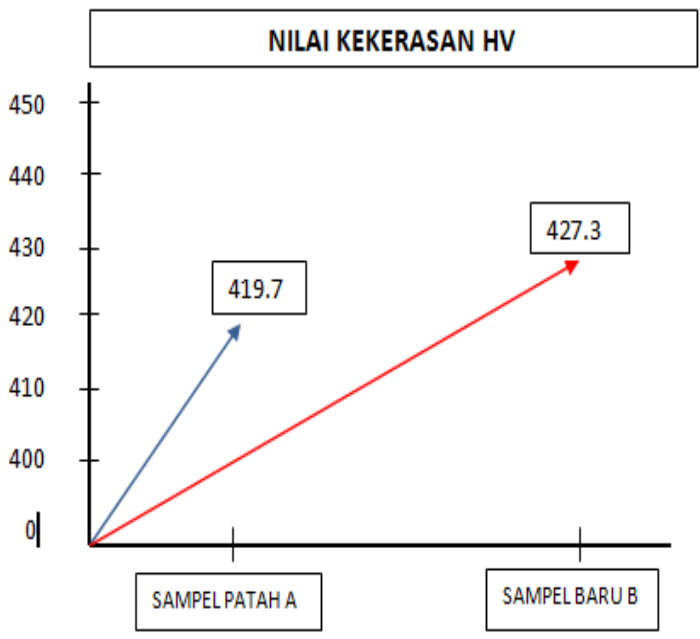

Figure 10. Hardness value graph

\section{Fractography Test}

From Figure 11, it can be seen that after performing a visual and macro inspection, the form of propagation that occurs in the leaf spring fracture with a magnification of $12 \mathrm{x}$ has begun to appear. In the macro photo of leaf spring fracture, the initial fracture occurs in the upper position, while the remaining fracture is in the part that experiences corrosion (bottom), this is in accordance with the working load. The initial fracture starts from the point (arrow) 
and it is seen that there is a fracture propagation structure in the form of a beachmark or shoreline line which is a characteristic of a fatigue fracture.

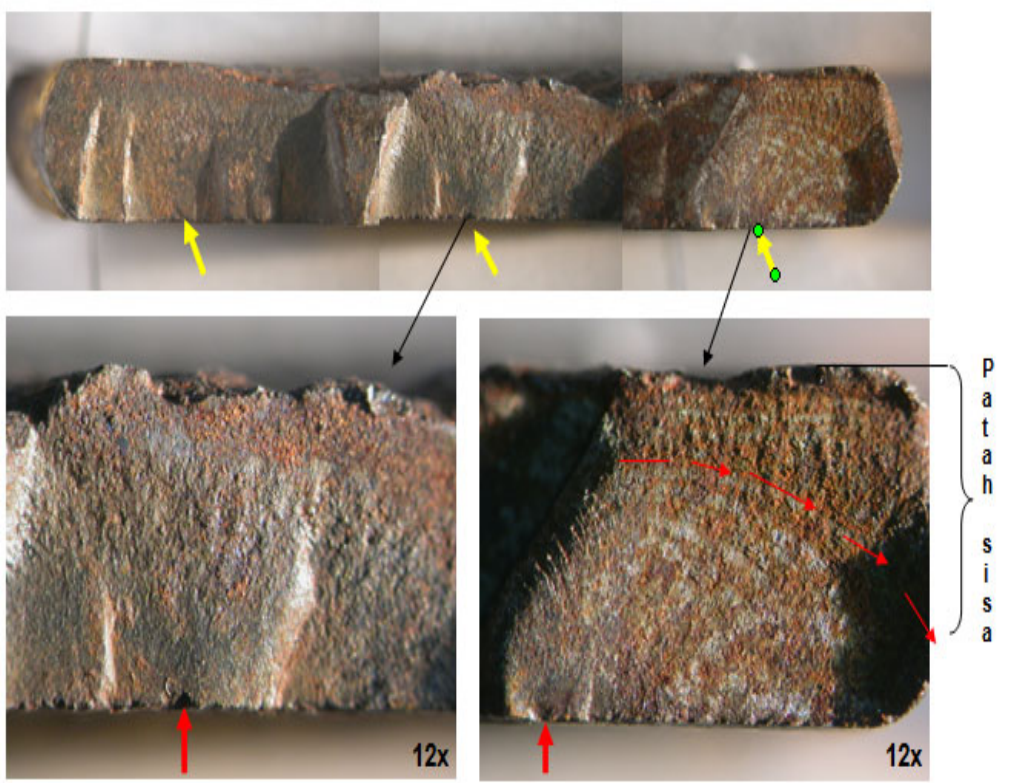

Figure 11. Macro photo of the leaf spring fracture surface

Figure 12 shows the microstructure of the broken sample A (edge) at the bottom of which there are many fatigue corrosion crackings, microstructure in the form of tempered martensite with transgrannular crackings. From macro observations, cracks occur in the lower direction of the leaf spring. Etching: nital 2\%.
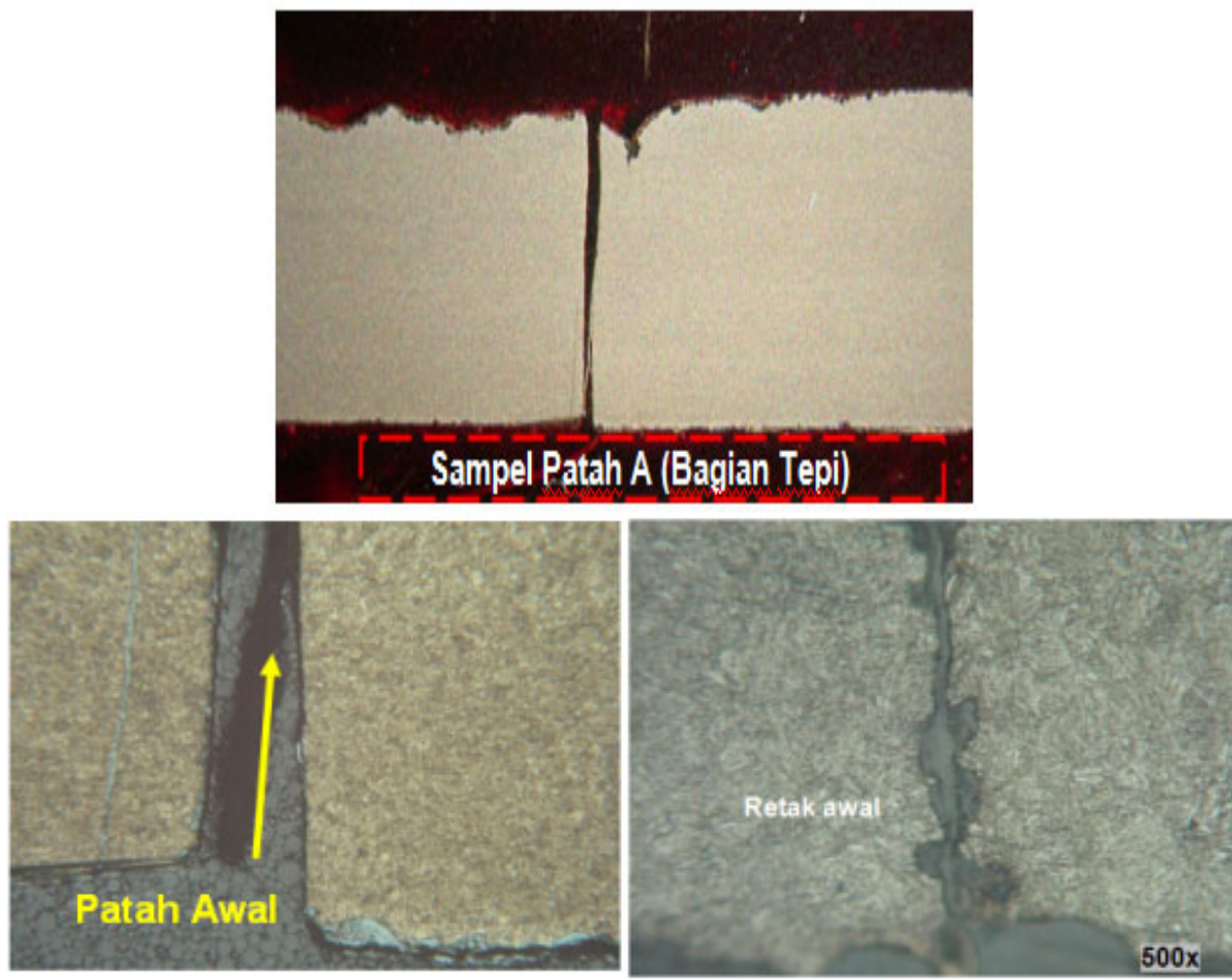

Figure 12. Microstructure of broken leaf spring in sample A (edge). 500x magnification.

Figure 13 is the residual fracture on the corrosion-affected surface (underside of leaf springs). At the bottom there is also a secondary crack which starts from a corrosion attack and there is a sedimentation of corrosion products. Micro structure in the form of tempered martensite. Etching: nital 2\% 


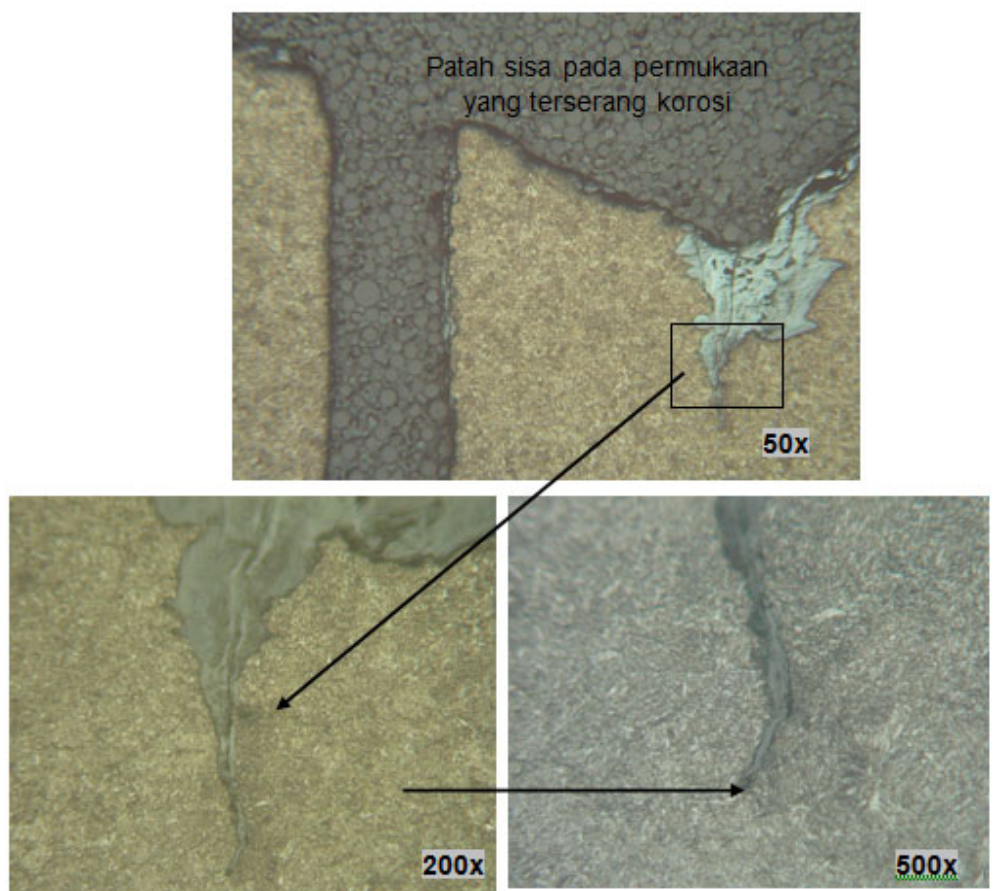

Figure 13. Micro structure of broken leaf springs with magnification of 50x, 200x and 500x

Figure 14 shows microstructure of fracture sample A (Middle Section) at the bottom of which there are many fatigue corrosion crackings with transgrannular crackings. The initial fracture starts from the center (fracture sample A) with a straight fracture. In the figure at 200x and 500x magnifications are also found other cracks. microstructure in the form of tempered martensite. Etching: nital 2\%
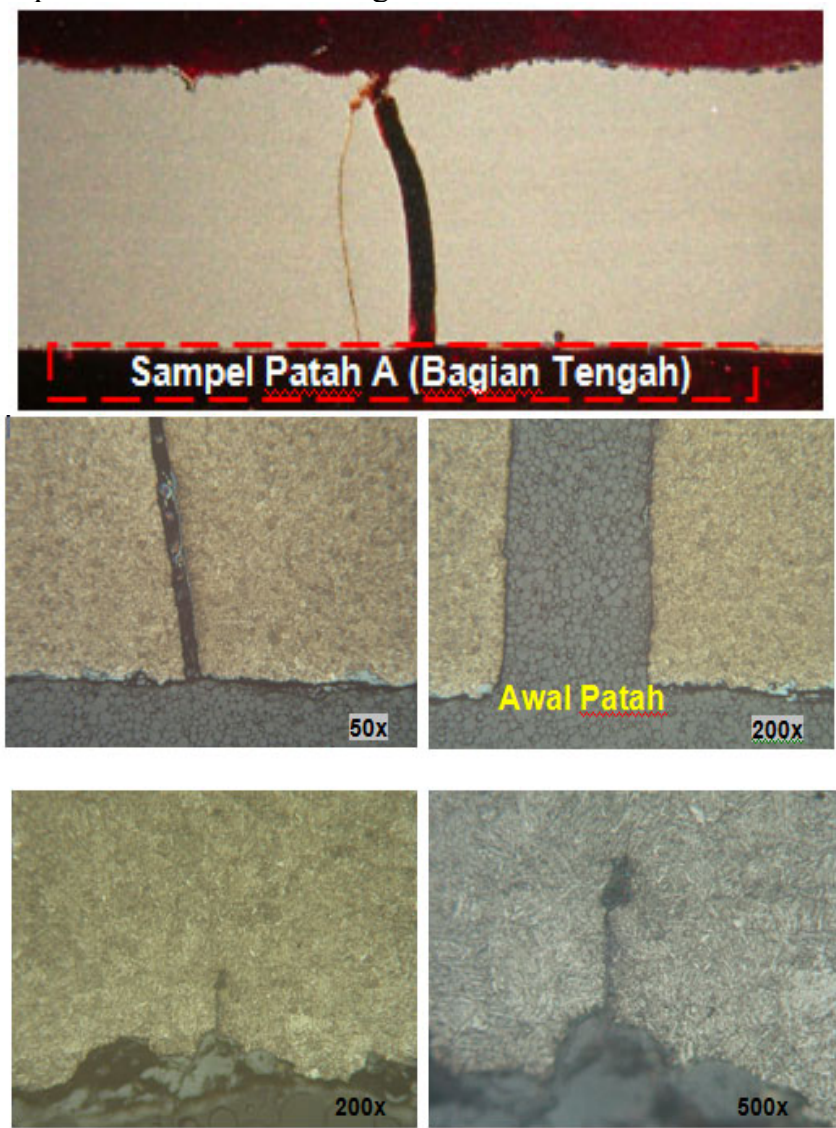

Figure 14. Micro structure of broken leaf springs with magnification of 50x, 200x and 500x

Figure 15 is the microstructure of fractured sample A (in the middle) with magnification of 50x and 200x. The micro structure is in the form of tempered martensite and it can be seen that in different locations crevice 
corrosion occurs. Etching: nital2\%
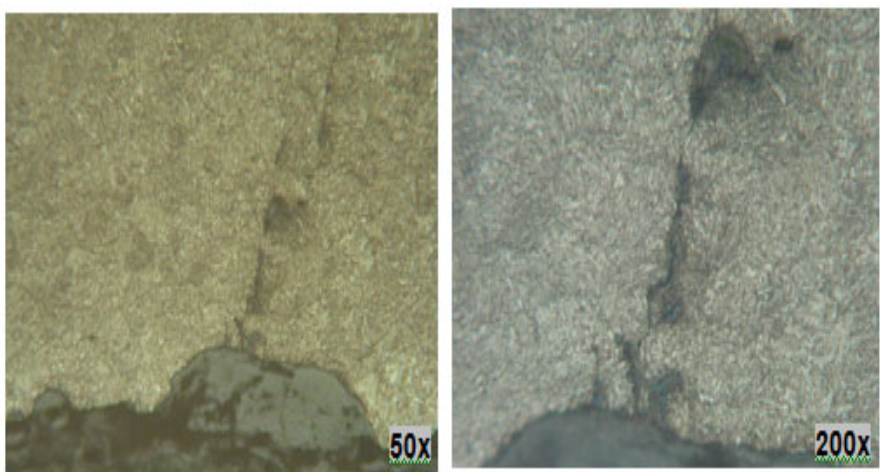

Figure 15. microstructure of fractured sample A (middle section) with 50x and 200x magnification

It can be seen in Figure 16 that the microstructure of the new sample B with 200x and 500x magnification at 3 location points where the microstructure that occurs is tempered martensite, there are no voids or other defects. Etching: nital 2\%.
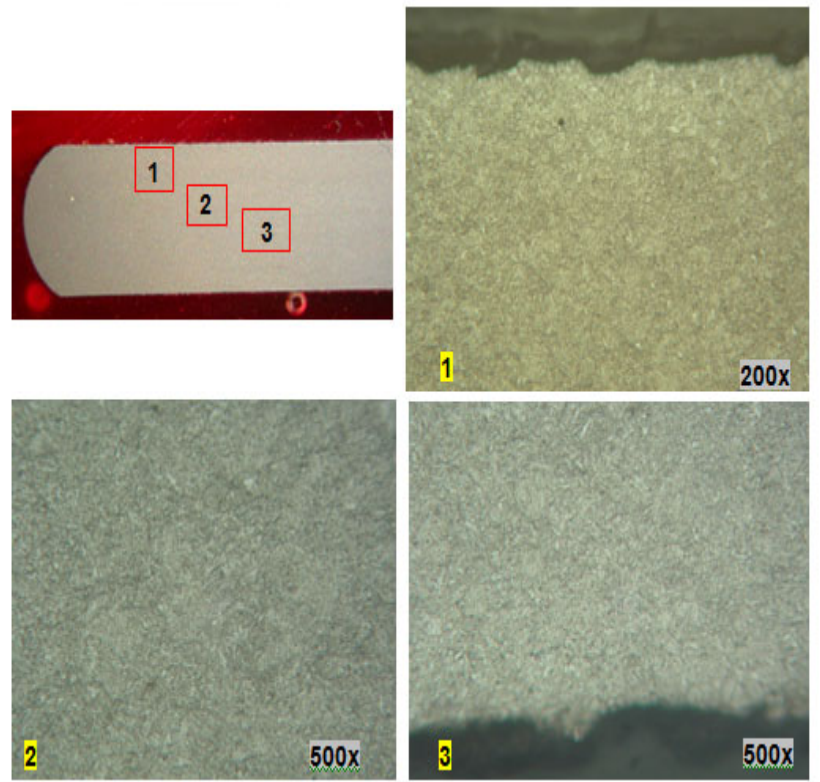

Figure 16. microstructure of new sample $B$ with 500x and 200x magnification

\section{CONCLUSION}

From the observation and analysis, several conclusions can be drawn including:

1. The chemical composition test results on medium carbon steel leaf springs shows it contained a dominant element, such as Iron (Fe) $97.52 \%$ and there were element of $0.714 \%$ Chromium $(\mathrm{Cr}$ ) alloy, 0.677\% Manganese (Mn) alloy, 0.297\% Silicon (Si) alloy, 0.121\% Copper (Cu) alloy and $0.470 \%$ Carbon (C).

2. The hardness Vickers hardness test results resulted in a comparison value of hardness, both for the fractured leaf spring material (Sample A) with an average of 419.7 and with the new leaf spring (Sample B) with an average of 427.3. The results of hardness testing on fractured sample A and new sample B did not experience any significant changes, the comparison value of leaf springs had no effect on hardness.

3. Metallographic test results on the microstructure condition of the fractured leaf spring Sample A (edge), the initial fracture occurred in the upper position of the leaf spring, while the remaining fracture occurred in the area affected by corrosion (the lower part of the leaf spring). At the bottom, there is a lot of fatigue corrosion crackings, microstructure in the form of tempered martensite with transgrannular crackings. From macro observations, cracks occur in the transverse direction of the leaf spring in the lower position. At the bottom there is also a secondary crack which starts from a corrosion attack and there is a deposit of corrosion products.

4. The results of the metallographic test of the microstructure condition of the fractured leaf spring sample A (middle part) were caused by an indication of the initial fracture of the upper position of the leaf springs where this position is the critical area in receiving dynamic loads during vehicle operation. The microstructure of the surface area experiencing corrosion attack (the underside of the leaf springs) is in 
the form of soft temper martensite and there is crecive corrosion with transgrannular cracks.

5. The results of the metallographic test on the microstructure of the new leaf spring (Sample B) did not show any voids or other defects, the micro structure in the form of tempered martensite.

6. From the results of fractography testing, the initial fracture occurred in the upper position of the leaf spring while the remaining fracture was at the edge of the leaf spring which was exposed to corrosion. The existence of a fracture propagation in the form of a beachmark or shoreline is a characteristic of a fatigue fracture.

\section{References}

1. Davis, HE; Troxell, GE. 1982. The Testing of Engineering Materials 4th edition. The McGraw-Hill International Book Company: New York

2. Djaprie, Sriati. 1993. Mechanical Metallurgy. Jakarta: Erlangga

3. Djoko Wijono, Practical Theory of Metal Science, LUK-BPP Technology, 1994.

4. Metal Handbook vol. 9, 'Fractrography and Atlas of Fractrographs', American Society for Metals, 1974

5. Engineeringxxx.blogspot.com/2013

6. Eprints.unlam.ac.id/fraktografi/2011

7. fatigue-life-prediction-google. 2012

8. http: //id.wikipedia .org / wiki / spring / 2012

9. id.wikipedia.org/wiki/Sistem_suspensi_(kendaraan) / 2010

10. Knowledgemention.blogspot.com/2022

11. Sites.google.com/2010 